\title{
CONTRIBUIÇÕES FORMATIVAS DO PROGRAMA INSTITUCIONAL DE BOLSA DE INICIAÇÃO À DOCÊNCIA (PIBID) NA DOCÊNCIA EM GEOGRAFIA
}

\author{
Josias Ivanildo Flores de Carvalho \\ Mestrando do Programa de Pós-graduação da UFPE \\ josias-ivanildo@hotmail.com \\ Dr. Francisco Kennedy Silva dos Santos \\ Universidade Federal de Pernambuco (UFPE) \\ kennedyufpe@gmail.com
}

Artigo recebido em 23/12/2017 e aceito em 06/01/2018

\begin{abstract}
RESUMO: A formação docente constitui-se como campo de investigação estratégico para compreensão das dinâmicas e processos associados diretamente a docência. Diante desta proposição e Apoiando-se em diversos estudos que tratam da importância da formação inicial em nível superior e de seus entrelaçamentos com as políticas públicas educacionais e seus desdobramentos com os programas formativos, nos colocamos diante do desafio de analisar de forma crítica-situacional os mecanismos de ação e de reestruturação em rede a partir do Programa Institucional de Bolsa de Iniciação à Docência (PIBID) no âmbito da formação inicial dos alunos do curso de licenciatura em Geografia de duas instituições (UFPE e UPE). Mediante as exigências do objeto optou-se pela pesquisa qualitativa. Por tratar-se de um trabalho de investigação em fase inicial, este artigo configura-se, portanto como pesquisa do tipo 'estado da arte' ou 'estado do conhecimento', que subsidiará as fases de campo.
\end{abstract}

Palavras-chave: Formação Docente; Licenciatura; PIBID; Prática Docente; Inovação Pedagógica.

\section{TRAINING CONTRIBUTIONS OF THE INSTITUTIONAL SCHOLARSHIP PROGRAM FOR TEACHING (PIBID) IN TEACHING IN GEOGRAPHY}

\begin{abstract}
Teacher training is a field of strategic research to understand the dynamics and processes directly associated with teaching. In the light of this proposition, and based on several studies that deal with the importance of initial formation at a higher level and its interrelations with public educational policies and their consequences for the training programs, we are faced with the challenge of critically and situationally analyzing the Mechanisms of action and of network restructuring from the Institutional Program of Initiation to Teaching Grant (PIBID) in the scope of the initial training of students of the degree course in Geography of two institutions (UFPE and UPE). Through the requirements of the object we opted for qualitative research. Since this is a research project in the initial phase, this article is therefore a state-of-the-art or state of the art research that will subsidize the field phases.
\end{abstract}

Key-words: Teacher Training; Graduation; PIBID; Teaching Practice; Pedagogical Innovation. 


\section{1 - INTRODUÇÃO}

As discussões sobre os processos formativos dos professores estão em análise desde 1920 quando houve uma grande preocupação para com a profissionalização dos docentes e com o passar das décadas os estudos voltados para formação docente sempre estiveram nos principais debates das políticas educacionais do Brasil, seja no ambiente universitário, nos questionamentos da sociedade e na busca dos professores por uma formação consistente que lhes permitam exercer uma prática docente significativa. Ao discutirmos a Educação e a Formação dos Professores de Geografia estamos mergulhando em um processo dialético que nos possibilita compreender a complexidade das questões educacionais existentes em nosso país.

As diretrizes que regulamentam a estrutura funcionalista das instituições que possuem cursos formadores de educadores foram modificadas, estabelecendo a necessidade de uma articulação direta com as gestões Federal, Estadual e Municipal nesse processo por meio da Lei de Diretrizes e Bases Nacional (LDBEN) de 1996 e do conjunto indissociável de resoluções e diretrizes alinhadas aos Parâmetros Curriculares Nacionais (PCNs) e as Diretrizes Curriculares Nacionais (DCNs).

O Estado brasileiro passa a enxergar a formação dos professores como prioridade para a obtenção de um país desenvolvido, no sentido cognitivo e econômico. Uma vez que, para se alcançar os resultados esperados na educação, estratégias devem ser traçadas de maneira conjunta, ou seja, governos, universidades e sociedade civil mobilizada.

Pensando na formação dos professores por um viés contínuo foi criado no ano de 2007 pelo Governo Federal junto a Coordenação de Aperfeiçoamento do Ensino Superior (CAPES) o Programa Institucional de Bolsa de Iniciação à Docência (PIBID), buscando valorizar a formação dos docentes para o ensino básico, capacitar continuamente os professores da rede pública e permitir um maior contato dos futuros docentes com o cotidiano escolar. Além disso, um dos propósitos centrais do programa é a superação do distanciamento das instituições públicas formadoras com as escolas públicas, realizando a conexão entre teoria e prática (ANDRÉ, 2012).

Assim o presente trabalho busca analisar de forma crítica-situacional os mecanismos de ação e de reestruturação em rede a partir do Programa Institucional de Bolsa de Iniciação à Docência (PIBID) no âmbito da formação inicial dos alunos do curso 
de licenciatura em Geografia de duas instituições de ensino superior do estado de Pernambuco (UFPE e UPE) e seus rebatimentos na iniciação à docência. Busca-se por meio desta investigação responder a seguinte questão: Qual a relação do PIBID Geografia na promoção da construção de um projeto de formação centrado nos dilemas da prática e suas interfaces para efetivação dos princípios pedagógicos da identidade, diversidade e autonomia, da interdisciplinaridade e da contextualização dos conceitos geográficos?

A proposta de pesquisa aqui apresentada configura-se como uma pesquisaformação. Mediante as exigências do objeto optou-se pela pesquisa qualitativa como trajeto a percorrer, dado que o fenômeno a ser pesquisado abarcará as ações sociais que raramente podem ser quantificadas. Desvelou-se que nos últimos oito anos inúmeros pesquisadores na área de Educação e Geografia tem se debruçado sobre a temática e da importância do PIBID no cenário das politicas de educação enquanto política 'jovem' e seus rebatimentos na formação de professores como, por exemplo, as recentes teses de doutorado em Educação de Rodrigues (2016) e Menezes (2017) que abordaram o referido programa. Anuncia-se de forma particular o ensino e a pesquisa como meios para o saber-fazer docente.

\section{2 - O ESTADO DA ARTE E SUA APROXIMAÇÃO COM O OBJETO DE PESQUISA}

O estado da arte pode ser compreendido como momento do investigador de se aproximar das teorias e estudos basilares para compreensão e fundamentação de seu objeto de investigação (ANDRÉ, 1994). Seguindo esta premissa, procuramos neste item uma aproximação teórico-conceitual da temática em jogo e de seus desdobramentos. A intenção não é esgotar nossas argumentações, mas fundamentar nosso problema de pesquisa.

Na Universidade Federal de Pernambuco (UFPE) o PIBID está em funcionamento desde 2009. Em 2015, o PIBID-UFPE contou com 625 licenciados de 16 cursos de licenciatura, 44 docentes desses cursos, contando com 24 subprojetos nos três campis da UFPE (Recife, Vitória e Caruaru), além de 90 professores da rede pública de ensino.

Já a Universidade de Pernambuco (UPE) vem desenvolvendo atividades no PIBID desde 2010 especificamente no campus Mata Norte (UPE), inicialmente com os cursos de Letras, Pedagogia e Matemática, a partir do ano de 2014 outras licenciaturas foram inseridas no projeto. Atualmente o PIBID-UPE (Nazaré da Mata, Campus Santo Amaro, 
Garanhuns e Petrolina) conta com 397 alunos, 46 supervisores/professores e 28 coordenadores (área, gestão e institucional).

Nesta pesquisa serão investigados os subprojetos Pibid-Geografia/UFPE - campus Recife que conta atualmente com 6 bolsistas, 1 supervisor e 1 coordenador de área, que realizam atividades de ensino, pesquisa e extensão no Ensino Médio. E o subprojeto PibidInterdisciplinar/UPE - campus Mata Norte, que conta com 17 alunos do curso de Geografia, e graduandos dos cursos de Letras, Matemática, Pedagogia e Ciências Biológicas, ou seja, envolve também as outras licenciaturas do campus, onde a cada ano trabalha com um determinado tema e assim desenvolvem atividades nas escolas da Rede Municipal e Rede estadual de Ensino Fundamental I e II e Ensino Médio.

As metodologias de ensino são fundamentais para que o docente consiga tecer práticas que contribuam no exercício da sua profissão de acordo com habilidades e competências necessárias para lidar com o ambiente escolar, sendo o mediador e articulador do conhecimento e estabelecendo estratégias que conduza o aluno a adquirir saberes formais e informais; a partir da empiria, pois todo sujeito carrega consigo experiências, vivências, saberes, uma história que deve ser aperfeiçoada na escola com os conhecimentos sistematizados das ciências (CAVALCANTI, 2008).

Porém, sabe-se que para se adquirir novas metodologias e alcançar práticas de ensino significativas os professores necessitam, no seu ambiente de trabalho, se inserirem num constante movimento reflexivo e investigativo para que, assim, seja possível inovar. Uma vez que há inúmeros desafios associados ao cotidiano do 'chão da sala de aula', tais como a intensa jornada diária de trabalho, a demanda grande de alunos e questões de ordem financeira, etc.

Diante disto, o educador precisa ser levado, a partir de um senso investigativo e na tentativa de transpor as dificuldades inerentes à escola, a buscar percursos teóricos que possibilitem a transição do tradicionalismo pedagógico para estabelecer uma prática que tencione o envolvimento de seus alunos nas aulas de Geografia, como abordam (MOREIRA, SILVA e FERREIRA, 2007, p. 73),

A sala de aula deve ser um espaço de construção e de troca de conhecimentos, onde se ensina e se aprende. Diferente do que pensam alguns profissionais, mesmo professores com domínio de conteúdo da disciplina sempre aprendem ao ensinar. O professor é o parceiro mais importante no processo de aprendizagem, pois ele pode incitar o grupo de alunos ao aprendizado, desafiá-los a serem pesquisadores 
permanentes, como pode também ser o responsável pela amputação intelectual, desistência e desânimo de uma turma inteira.

Tendo como base esta constatação do professor que conduz os discentes no processo de aperfeiçoamento dos seus conhecimentos e saberes, fica a responsabilidade para que os mesmos aprimorem suas práticas e metodologias nas suas aulas, uma vez que estamos diante de uma sociedade cada dia com maior acesso às informações, seja por meio da TV, Internet, mídias digitais, rádio, entre outras fontes, que levam muitas vezes os alunos e a própria sociedade em geral a enxergar a escola como um ambiente arcaico em meio ao mundo repleto de novas fontes de conhecimento. Libâneo (2001) denomina a sociedade atual como sendo eminentemente pedagógica, já que há práticas pedagógicas e ações pedagógicas em todos os meios sociais.

O papel da escola e dos professores é testado pelos os que esperam do sistema educacional soluções para os problemas enfrentados pela sociedade, uma vez que almejam que os indivíduos aperfeiçoem seus conhecimentos para adentrar no mercado de trabalho. Pois na sociedade capitalista atingir o patamar de poder perpassa pelas salas de aulas e pelos professores, recaindo assim toda responsabilidade na educação. Na realidade, alguns indivíduos da sociedade desconhecem a verdadeira função social da escola, que não se resume ao dinheiro e competitividade, estamos falando da educação para a cidadania, mas que não despreze os saberes empíricos dos sujeitos e sistêmicos das ciências.

As práticas e as metodologias dos docentes em Geografia devem ser aprimoradas para envolver os educandos nas aulas, apresentando-lhes o verdadeiro significado da disciplina para a sociedade. Como salienta Cavalcanti (2008, p. 37), "na prática, enfim continua sendo um desafio cumprir o objetivo básico da geografia na escola, que é o de formar um pensamento geográfico, pensamento espacial genericamente estruturado para compreender e atuar na vida cotidiana pessoal e coletiva”. Assim, Freire (2001) discute um processo pedagógico inclusivo que forme os estudantes para a cidadania acima de tudo, e que lhes capacitem para mudar as distorções existentes na sociedade.

Seguindo por este viés, Vieira e Sá (2007) apontam que as metodologias de ensino podem ser aqui entendidas como a "forma" que o professor pretende desenvolver um conteúdo junto aos seus alunos para alcançar um objetivo de aprendizagem em uma determinada disciplina, neste caso, na Geografia.

Os Parâmetros Curriculares Nacionais (PCNs, 1998) de Geografia ressalta a importância dos professores em ultrapassar as tradicionais aulas expositivas ou apenas a 
utilização do livro didático, em que situações problematizadoras devem ser criadas para se trabalhar com diferentes temas como: o espaço e as paisagens geográficas do passado e do presente. $\mathrm{O}$ ambiente da sala deve proporcionar aos alunos segurança e confiança para estudar, pedir ajuda, que possam despertar potencialidades criativas, compartilhar experiências e conhecimentos, autonomia, organização entre tantos outros que a dinâmica da sala de aula proporciona aos alunos e professores um trabalho com significado.

Inúmeros instrumentos podem ser consultados e introduzidos pelos professores nas suas aulas para que as mesmas se tornem mais atrativas como a utilização de jogos, vídeos, informática, música, literatura, dramatização, produção de curtas, criação de mapas sociais, que possibilitam um ambiente dinâmico, inclusivo e que permita a construção de saberes a partir do diálogo entre aluno e professor, como anunciam Carlos (2008); Vieira e Sá (2007); Cavalcanti (2002); Castrogiovanni, Rego e Kercher (2007), que acreditam na possiblidade de os professores poderem (re)criar práticas e metodologias prazerosas para que os seus alunos possam enxergar os fenômenos geográficos a partir de suas realidades vividas, percebidas, materiais e imateriais.

Posto isto, nota-se que o professor passa a assumir um papel de pesquisador de suas práticas, dos seus métodos de ensino, já que apenas a dominação dos conteúdos não assegura ao profissional em educação a eficácia para que os alunos aprendam da melhor forma e possam notar também que estudar geografia é necessário para o seu desenvolvimento enquanto cidadão atuante em seu espaço. É assim que esse professorpesquisador-reflexivo surge para atender a demanda de um novo alunado dentro de uma escola com traços do século passado. Marli André traz esse posicionamento, ao afirmar que:

A tarefa do professor no dia-a-dia de sala de aula é extremamente complexa, exigindo decisões imediatas e ações, muitas vezes, imprevisíveis. Nem sempre há tempo para distanciamento e para uma atitude analítica como na atividade de pesquisa. Isso não significa que o professor não deva ter um espírito de investigação. É extremamente importante que ele aprenda a observar, a formular questões e hipóteses e as selecionar instrumentos e dados que o ajudem a elucidar seus problemas e a encontrar caminhos alternativos na sua prática docente. (ANDRÉ, 2001, p. 59).

As metodologias de ensino serão objeto de sua investigação e reflexão situada, visto que a sala de aula será para esses professores-pesquisadores o seu laboratório, tendo o intuito de aperfeiçoar suas metodologias de ensino e, consequentemente, suas práticas. 
Além de poder contar com os demais professores para que, de maneira conjunta, possam buscar alternativas para que o ensino seja cada vez mais aprimorado e a intersubjetividade se torne o percurso de emancipação de suas práticas, como apontam Gallo e Rivero (2004, p. 47) “É importante que o professor capacite-se para a pesquisa e a produção de conhecimentos, transformando e buscando novas metodologias que the possibilitem desenvolver um trabalho pedagógico interdisciplinar, transdisciplinar e não como compartimentos estanques".

É transitando entre paradigmas que o professor e os futuros mestres podem criar uma nova maneira de ensinar, que abarque a pesquisa, a formação contínua e o ensino interdisciplinar (CUNHA, 1998), pois é por meio de abordagens que fogem ao "tradicional" que o aluno se vê como um participante do processo de ensino e aprendizagem, tornando possível um ensino geográfico problematizador e que estabeleça diálogos com as demais disciplinas, abarcando, desta maneira, um conhecimento interligado e não fragmentado como ressalta Pontuschka, Paganelli e Cacete,

\begin{abstract}
A interdisciplinaridade como princípio e atitude interdisciplinar constitui foco de discussão para pesquisadores e educadores dos vários níveis de ensino, que, ao reconhecerem a complexidade do mundo pós-industrial e o processo de globalização vivenciado pelos povos do mundo inteiro, estão cientes que os saberes parcelares não dão conta de resolver problemas que demandam conhecimentos específicos, relacionados a um objeto comum e central. (PONTUSCHKA, PAGANELLI e CACETE, 2009, p. 143-144).
\end{abstract}

É a partir dessa visão interdisciplinar que envolve a desconstrução das práticas trabalhadas por professores da educação básica, que ainda em sua maioria possuem a convicção que os alunos são meros receptores de conhecimentos, trabalhando com metodologias impostas por um modelo educacional que muitas vezes não envolvem os alunos em suas aulas. Criando-se dessa maneira um ambiente escolar não favorável para o desenvolvimento das habilidades cognitivas e emocionais dos alunos.

Desta forma, o Programa Institucional de Bolsa de Iniciação à Docência (PIBID), juntamente com a Coordenação de Aperfeiçoamento do Ensino Superior (CAPES) assegurados pelas leis e decretos a seguir (Lei $\mathrm{n}^{\circ} 11.502$, de 11 de julho de 2007) que tem a finalidade de valorizar o magistério e apoiar os estudantes de licenciatura das instituições públicas e comunitárias, sem fins ou com fins econômicos, de educação superior; o decreto (Decreto $\mathrm{n}^{\circ}$ 6.094, de 24 de abril de 2007) que atende às diretrizes do Plano e Metas 
Compromisso Todos pela Educação; e também o decreto e a lei que estabelece os princípios da Política Nacional de Formação de Profissionais do Magistério da Educação Básica (Decreto $\mathrm{n}^{\circ} 6.755$, de 29 de janeiro de 2009 e Lei $\mathrm{n}^{\circ} 11.947$, de 16 de junho de 2009, no seu Art. 31) e de normas do MEC e atribuições legais da CAPES, tornando-se um aliado na construção de uma nova educação.

É por meio da concepção que a educação deve ser entendida como uma rede de aprendizagem onde todos os autores do processo de ensino-aprendizagem, e a sociedadecivil devem contribuir para um ensino inovador e consequentemente uma aprendizagem significativa que contribua de maneira conjunta para a formação inicial e contínua dos professores de Geografia e demais licenciaturas por meio do PIBID.

\section{3 - CONSIDERAÇÕES FINAIS}

Os questionamentos sobre os processos de formação dos professores de Geografia e das demais licenciaturas não se encerram, mas se iniciam constantemente a partir da criação do Programa Institucional de Bolsa de Iniciação à Docência (PIBID), visto que, as contribuições do citado programa para a reafirmação da identidade docente, valorização docente, formação contínua, além do maior diálogo entre as universidades e as escolas e na efetivação de práticas inovadoras que dialoguem com os alunos e os saberes sistêmicos das ciências que surgem diariamente.

Sendo o PIBID uma política "nova de Estado" o mesmo já começa a dar frutos positivos para a educação, pois inúmeros são os novos licenciados (as) e licenciandos (as) que poderam e podem ter acesso ao programa, podendo assim tem uma formação mais completa, reflexiva, inovadora, crítica e participativa na tentativa de melhorar o quadro da educação pública do Brasil na contemporaneidade.

Ao refletirmos sobre a formação dos professores de Geografia estamos tentando avançar nas possíveis contribuições que uma formação consistente pode oferecer aos docentes em suas aulas, dado que os fenômenos/conceitos geográficos são trabalhados ainda na maioria das vezes a partir da memorização e da descrição. Não é que esses meios não sejam necessários ou válidos, porém defendemos que o ensino da Geografia seja o mais crítico e problematizador possível na busca incessante de formar cidadãos conscientes, ativos e participativos das questões sócio-políticas e ambientais da nossa sociedade local-mundial. 
Dessa maneira, a formação de professores de Geografia no contexto atual deve-se pautar na reflexão de suas práticas que se dará a partir de uma formação sólida e que se possível atrelada à participação dos licenciados (as) e professores (as) da educação básica ao PIBID uma vez que esse é o único programa oficial do Brasil em escala nacional que se propõe a formar e capacitar bons professores para atuarem na educação básica.

Existe uma necessidade de maiores investimentos financeiros por parte da União para que o programa PIBID possa ser expandido para todos os alunos de instituições públicas e privadas sem fins lucrativos para que realmente possamos ter uma formação inicial motivadora, uma formação contínua que seja praticada e que a educação possa voltar a ter seu prestígio e seu valor reconhecido pelos que a fazem e por aqueles que dela desfrutam.

Ao estudarmos a literatura da educação nos deparamos com comparações entre a profissão do médico (a) e a do professor (a) na obra Geografia e Didática na primeira página tem a seguinte passagem:

Pior ainda, não se exerce a medicina sem um estágio de "residência", onde efetivamente se aprende o exercício realista e concreto da profissão, enquanto que para a maior parte dos alunos que buscam ser professores raramente se cobram estágios e, se a exigência se impõe, todos sabemos com que facilidade é a mesma escamoteada. (SELBACH, et al. 2014, p. 7).

Dessa forma, é evidenciado que os motivos que levaram ao desprestígio docente, o sucateamento das escolas, a desvalorização social e financeira da classe e a não política de formação permanente dos professores brasileiros são o reflexo de uma educação que necessita ainda lutar, e a criação do PIBID é o recomeço para alcançarmos a educação pública de qualidade que os brasileiros desejam. Mesmo estando inseridos em uma política econômica neoliberal podem-se mudar os rumos da educação no Brasil, uma vez que existem as resistências frente ao projeto de não educação cidadã que há décadas sufoca o sistema público de ensino brasileiro.

\section{REFERÊNCIAS BIBLIOGRÁFICAS}

ANDRÉ, M.E.D.A. Etnografia na prática escolar. Campinas: Papirus, 1994. 
Políticas e programas de apoio aos professores iniciantes no Brasil. CADERNOS DE PESQUISA. v.42 n.145 p.112-129 jan./abr. 2012. 2001.

O papel da pesquisa na formação e na prática dos professores. Campinas- SP: Papirus,

BRASIL. Lei de Diretrizes e Bases da Educação Nacional: n 9394/96. Brasília, 1996.

Decreto ${ }^{\circ}$ 6.094, de 24 de abril de 2007.

Decreto $\mathrm{n}^{\circ} 6.755$, de 29 de janeiro de 2009, e Lei ${ }^{\circ} 11.947$, de 16 de junho de 2009, no seu Art. 31.

Lei $\mathrm{n}^{\circ}$ 11. 502, de 11 de julho de 2007 que modifica as competências e a estrutura organizacional da fundação Coordenação de Aperfeiçoamento de Pessoal de Nível Superior CAPES.

Parâmetros Curriculares Nacionais. Brasília, 1998.

CARLOS, A. F.(org). A Geografia na sala de aula. $8^{\circ}$ ed. São Paulo: Contexto, 2008.

CAVALCANTI, L. de S. Geografia e práticas de ensino. Goiânia, ed.: Alternativa, 2002.

A geografia escolar e a cidade: ensaios sobre o ensino de geografia para a vida urbana cotidiana. Campinas-SP: Papirus, 2008.

CUNHA, M. I. O professor universitário na transição de paradigmas. Araraquara: JM editora, 1998.

FREIRE, P. A educação na Cidade. $5^{\circ}$ ed. São Paulo: Cortez, 2001.

LIBÂNEO, C. J. Pedagogias e Pedagogos: inquietações e buscas. Curitiba, n. 17, p. 153-176. 2001.

MENEZES, E. A. O. A PESQUISA COMO POTENCIALIZADORA DA REFLEXÃO CRÍTICA SOBRE A FORMAÇÃ̃ E A PRÁTICA DOCENTE: um olhar sobre a experiência formativa do PIDIB-UECE, Tese de Doutorado, PPGE-UECE. Ceará, 2017.

MOREIRA, S. D.; SILVA, J. M.; FERREIRA, J. R. A didática da afetividade. In: PASSINI, Y. E.; PASSINI, R.; MALYSZ, T. S. (Org). Prática de ensino de geografia e estágio supervisionado. São Paulo: Contexto, 2007.

POntUSChKa, N. N.; PAGANElli, T. Y.; CACETE, N. H. Para ensinar e aprender Geografia. $3^{\circ}$ ed. São Paulo: Cortez, 2009.

REGO, N.; CASTROGIOVANNNI, C. A.; KAERCHER, A. N. Geografia práticas pedagógicas para o ensino médio. Porto Alegre: ed. Artmed, 2007.

RIVERO, Célia Maria; GALLO, Silvio (Orgs) A formação de professores na sociedade do conhecimento. Bauru, SP:EDUSC, 2004.

RODRIGUES, C. S. D. PROFESSORES ORIENTADORES DE INICIAÇÃO À DOCÊNCIA NO PIBID: TRAJETÓRIA FORMATIVA E TESSITURAS DA RACIONALIDADE 
PEDAGÓGICA NA DOCÊNCIA UNIVERSITÁRIA. Tese de Dourado, PPGE-UECE. Ceará, 2016.

SELBACH, et al. Geografia e Didática. 2. Ed.- Petrópolis, RJ: Vozes, 2014.

VIEIRA, E. C.; SÁ, G. M. Recursos didáticos: do quadro-negro ao projetor, o que muda? In: PASSINI, Y. E.; PASSINI, R.; MALYSZ, T. S. (Org). Prática de ensino de geografia e estágio supervisionado. São Paulo: Contexto, 2007. 